\title{
The Key Role of the Electronic Control Technology in the Exploitation of the Alternative Renewable Fuels for Future Green, Efficient and Clean Diesel Engines
}

\author{
Carlo Beatrice, Silvana Di Iorio, Chiara Guido and Pierpaolo Napolitano \\ Istituto Motori, CNR, Naples \\ Italy
}

\section{Introduction}

Great concerns are growing up on environmental impact of fossil fuel and poor air quality in urban areas due to traffic-related air pollution. In the last years, special attention was paid mainly to particulate matter (PM) and NOx emissions of diesel engines since these pollutants are associated to environmental and health issues. In particular, NOx contributes to the formation of ozone and acid rains and PM could cause injuries to the pulmonary and the cardiovascular systems. Nowadays, the overall concern about the global warming determines an increased interest also for $\mathrm{CO}_{2}$ emissions, one of the major greenhouse gas (GHG). In this respect, a significant improvement can be reached with the increased use of "clean" and renewable fuels. It is well known, in fact, that the use of biofuels can contribute to a significant well-to-wheel (WTW) reduction of GHG emissions. The most interesting biofuel is the biodiesel and the fuels synthesised from fossil or biogenic gas.

Biodiesel designates a wide range of methyl-esters blends and is generally indicated with the acronym FAME, Fatty-Acid Methyl Esters. Biodiesel is produced from vegetable oils and animal fats through the transesterification, an energy efficient process that gives a significant advantage in terms of $\mathrm{CO}_{2}$ emission and that features both high energy conversion efficiency and fuel yield from processed oil. These two characteristics are the main responsible for the overall GHG emissions benefit of biodiesel in WTW analyses [1].

More recently, starting from the well-known Fischer-Tropsch synthesis process, another generation of alternative diesel fuel was developed. It is usually indicated with XTL, where $X$ denotes the specific source feedstock and TL (to Liquid) highlights the final liquid state of the fuel. It has minor interferences with the human food chain, since non-edible biomasses can be employed or, in case of animal-edible biomasses, the whole plant can be processed, as for the cellulosic ethanol production.

From the engine fuelling point of view, the significant difference between the two biofuels lies in their chemical composition. The first is essentially a blend of methyl-esters and the second of paraffin and olefin hydrocarbons. Because of the growing concerns about the energy crops impact on environment and food price, an increasing number of countries and stakeholders have recently challenged FAME biofuels. On the contrary, the XTL fuels, which 
show high energy yield in the production process as well as the capability to extend input feedstock to cellulosic biomasses, are considered very attractive [2]. Within this framework, biofuel producers and OEMs are jointly devoting significant efforts in optimizing benefits from first generation biofuels while making second generation technologies economically viable soon. In particular, in order to enlarge biofuel market penetration, common fuel standards need to be defined and the compatibility of the engines with biofuels improved. Biodiesel is the most important type of alternative fuels used in compression ignition engines because of its advantages in terms of emission reduction without significant changes to engine layout $[3,4,5]$ and, at the same time, for being partly bound by future European legislation [6]. Anyway, several studies showed that the impact of biodiesel on the modern diesel engines is significant also in terms of engine performance mainly because of the interaction between the biodiesel characteristics and the engine-management strategies $[7,8]$. One of the main differences of FAME with respect to petro-based diesel fuel is its oxygen content. It exceeds $10 \%$ of the total mass and it is directly responsible of the Low Heating Value (LHV) reduction of the same magnitude and eventually of the engine performance loss of about $12-15 \%$ at rated power and up to $30 \%$ in the low end torque. An efficient use of alternative diesel fuels, allowing to fully exploit all their potentials, can only be achieved through an "ad hoc" calibration of engine parameters and its control strategy (injection set and EGR rate) [8].

To create a flexible engine that can work efficiently both with conventional diesel and with biodiesel, it appears extremely important to develop a system able to detect the diesel biodiesel blending ratio present in the fuel tank and, automatically, to adapt engine calibration in order to fully exploit the fuel properties. In this respect, the adoption in the modern engines of the last recent combustion control methodology, named Closed Loop Combustion Control (CLCC) and based on the engine torque control by means of the instantaneous cylinder pressure measurement of the Electronic Control Unit (ECU) [8], has opened new scenarios for the development of the actual flex-fuel diesel engines.

On the basis of the previous experiences $[5,8]$, specific research activities were addressed to exploit and assess the capabilities offered by the CLCC technology in the development of the flex-fuel diesel engine.

The investigation was focused on three main aspects:

- development of a biodiesel-diesel blending detection (BD) methodology;

- mitigation of the impact of alternative fuels on emissions;

- exploitment of the alternative fuel quality for engine performance improvement.

The investigation was carried out on a 2.0L Euro5 diesel engine equipped with embedded pressure sensors in the glow plugs. Various blends of biodiesel were tested, notably $20 \%$ by volume (B20), 50\% (B50) and pure biodiesel (B100). Tests on the multi-cylinder engine were carried out in a wide range of engine operating points for the complete characterization of the biodiesel performance in the New European Driving Cycle (NEDC) cycle.

\section{Fuels}

The measurements were performed fuelling the engine both with pure fuels and blends to achieve a reliable biodiesel blending detection. The reference diesel fuel (RF) was an EU certification diesel fuel (CEC, RF-03-A-84) compliant with EN590, while the tested biodiesel was an EU-widely-available Rapeseed Methyl ester (RME) compliant with EN14112. Table 1 reports some of the most important parameters of the pure fuels. 
The Key Role of the Electronic Control Technology in the Exploitation of the Alternative Renewable Fuels for Future Green, Efficient and Clean Diesel Engines

\begin{tabular}{|l|l|r|r|r|}
\hline Feature & Method & & RF & RME100 \\
\hline A/Fst & & & 14.54 & 12.44 \\
\hline $\begin{array}{l}\text { Low Heating Value } \\
{[\mathrm{MJ} / \mathrm{kg}]}\end{array}$ & $\begin{array}{l}\text { ASTM D } \\
4868\end{array}$ & & 42.965 & 37.570 \\
\hline \multicolumn{1}{|c|}{ Carbon [\%, m/m] } & $\begin{array}{l}\text { ASTM D } \\
5291\end{array}$ & & 85.220 & 77.110 \\
\hline Hydrogen [\%, m/m] $]$ & $\begin{array}{l}\text { ASTM D } \\
5291\end{array}$ & & 13.030 & 11.600 \\
\hline Nitrogen [\%, m/m] & $\begin{array}{l}\text { ASTM D } \\
5291\end{array}$ & & 0.040 & 0.030 \\
\hline Oxygen [\%, m/m] & $\begin{array}{l}\text { ASTM D } \\
5291\end{array}$ & & 1.450 & 11.250 \\
\hline Cetane Number & $\begin{array}{l}\text { EN ISO } \\
5165\end{array}$ & & 51.8 & 52.6 \\
\hline $\begin{array}{l}\text { Density @ } 15^{\circ} \mathrm{C} \\
{[\mathrm{kg} / \mathrm{m} 3]}\end{array}$ & $\begin{array}{l}\text { EN ISO } \\
12185\end{array}$ & & 833.1 & 883.1 \\
\hline $\begin{array}{l}\text { Viscosity @ } 40{ }^{\circ} \mathrm{C} \\
{[\mathrm{mm} 2 / \mathrm{s}]}\end{array}$ & $\begin{array}{l}\text { EN ISO } \\
3104\end{array}$ & & 3.141 & 4.431 \\
\hline
\end{tabular}

\begin{tabular}{|c|c|c|c|c|}
\hline Feature & Method & & RF & RME100 \\
\hline Distillation $\left[{ }^{\circ} \mathrm{C}\right]$ & \begin{tabular}{|l} 
EN ISO \\
3405
\end{tabular} & IBP & 158.9 & 318.0 \\
\hline${ }^{\circ} \mathrm{C}$ & & $10 \%$ vol. & 194.3 & 331.0 \\
\hline${ }^{\circ} \mathrm{C}$ & & $50 \%$ vol. & 267.6 & 335.0 \\
\hline${ }^{\circ} \mathrm{C}$ & & $90 \%$ vol. & 333.4 & 344.0 \\
\hline${ }^{\circ} \mathrm{C}$ & & $95 \%$ vol. & 350.0 & 353.0 \\
\hline${ }^{\circ} \mathrm{C}$ & & FBP & 360.9 & 355.0 \\
\hline $\begin{array}{l}\text { Oxydation stability } \\
{[\mathrm{mg} / 100 \mathrm{ml}]}\end{array}$ & $\begin{array}{l}\text { EN ISO } \\
12205\end{array}$ & & - & 0.6 \\
\hline $\begin{array}{l}\text { Oxydation Thermal } \\
\text { Stability @ } 110^{\circ} \mathrm{C}[\mathrm{h}]\end{array}$ & EN 14112 & & - & 6.5 \\
\hline C.F.P.P. $\left[{ }^{\circ} \mathrm{C}\right]$ & EN 116 & & - & -14 \\
\hline Lubricity @ 60 $\mathrm{C}[\square \mathrm{m}$ & $\begin{array}{l}\text { EN ISO } \\
12156-01\end{array}$ & & - & 179 \\
\hline $\mathrm{POV}[\mathrm{meq} \mathrm{O} 2 / \mathrm{Kg}]$ & NGD Fa 4 & & & 16.60 \\
\hline TAN $[\mathrm{mg} \mathrm{KOH} / \mathrm{g}]$ & $\begin{array}{l}\text { UNI EN } \\
14104\end{array}$ & & & 0.13 \\
\hline
\end{tabular}

Table 1. Main fuel parameters

The combustion and the exhaust gas properties are mainly influenced by the lower LHV and stoichiometric air fuel ratio (A/Fst) of the RME fuel with respect the RF fuel due to the higher oxygen content of biodiesel. Moreover, RME's higher density and viscosity, coupled with its distillation curve stretched in the temperature interval corresponding to the hightemperature boiling fractions of conventional diesel, increase significantly the penetration of its sprays with respect to the reference diesel, especially in cold conditions. Spray overpenetration is actually one of the most important concerns of diesel-FAME blends because it leads to increased oil dilution, as well as risks of piston and liner scuffing. Furthermore, higher boiling curve of biodiesel leads to higher resident time of fuel in the oil. Such drawback could be even more critical in case of specific injection strategies involving late injections in the exhaust stroke, as for example the DPF/DeNOx regeneration. In such cases, fuel injection occurs in low-density charge and is targeted well above the bowl edge: experimental verifications reported in literature using pure biodiesel have assessed an oil dilution rate up to three times the baseline, depending on engine type, operating conditions and injection strategy [9].

\section{Experimental apparatus and test plan}

The main characteristics of the adopted four-cylinder in-line Euro5 diesel engine are reported in Table 2. The Euro 5 engine features the closed-loop combustion control (CLCC), which enables individual and real-time control of the angular position corresponding to the $50 \%$ of Burned Fuel Mass, with respect to the top dead center (MFB50) and the Indicated Mean Effective Pressure (IMEP), cycle-by-cycle and cylinder-by-cylinder. In particular, based on in-cylinder pressure traces, heat release rate analysis is performed by ECU EDC17 using proprietary algorithms. The actual values for MFB50 and IMEP are compared to the target ones. As a consequence, the deviations of these two parameters are continuously resettled by adjusting the main injection timing and quantity for the following combustion cycle [10]. Based on these operating characteristics, the CLCC technology has been employed in order to develop a new diesel-biodiesel BD methodology, to mitigate or improve the engine emissions and increase the full load engine performance.

The engine was installed on a dyno test bench fully instrumented for indicated signal measurements (cylinder pressure, injection pressure, energizing injector current). Such 
measurements were carried-out by means of an AVL-based indicating acquisition system with an high-accuracy pressure sensor fitted on first cylinder, that was used as reference for validating the accuracy of the ECU-based CLCC. At the engine exhaust, smoke was measured by a high-resolution (0.01 filter smoke number, FSN) smoke meter (AVL415S), while gaseous emissions were measured upstream and downstream of the diesel aftertreatment device by means of a raw emission analysis test bench (AVL-CEB-2).

\begin{tabular}{|c|c|}
\hline Engine type & 4 cylinders in-line \\
\hline Certification & EURO5 \\
\hline Bore $\times$ Stroke [mm] & $83 \times 90$ \\
\hline Compression Ratio & 16.5 \\
\hline Valves per cylinder & 4 \\
\hline $\begin{array}{c}\text { Rated power and } \\
\text { torque }\end{array}$ & $\begin{array}{c}118 \mathrm{~kW} @ \text { @ 4000rpm } \\
\text { 380Nm @ 2000rpm }\end{array}$ \\
\hline Injection system & Common Rail \\
\hline Injector and nozzle & $\begin{array}{c}\text { Solenoid CRI 2.2+, 7 } \\
\text { holes }\end{array}$ \\
\hline Turbocharger & $\begin{array}{c}\text { Single stage VGT } \\
\text { Integrated } \\
\text { DPF }\end{array}$ \\
\hline Catalyst system & $\begin{array}{c}\text { closed-coupled DOC } \\
\text { DPF }\end{array}$ \\
\hline
\end{tabular}

Table 2. Main features of the engine

For all fuel blends, the engine was tested in nine steady-state operating points (k-points). The first seven test points were selected as the most representative of the engine operation on NEDC when matched to a D-class vehicle (1590kg IW). The eighth $(2500 \mathrm{rpm}$ at $16 \mathrm{bar}$ of BMEP) and ninth (2500 rpm full load) test points were devoted to the characterization of the engine performance in real life aggressive driving.

The selected NEDC k-points are summarized in Figure 1, where the operating area of the engine running over NEDC is also displayed.

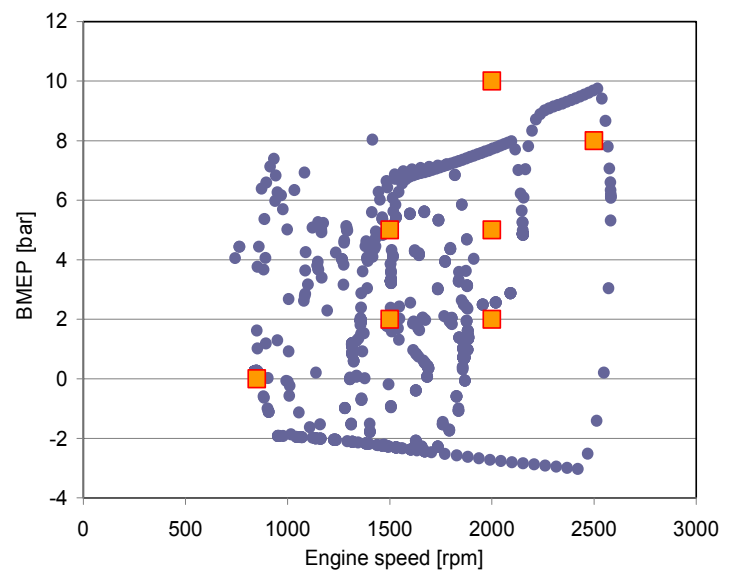

Fig. 1. Test points (k-points) together with the entire speed/load trace of the engine over NEDC for a D-class vehicle. 
The measurements in the seven part-load test points enabled the NEDC-cycle vehicle performance estimation for all fuel blends by means of a well consolidated correlation procedure between the specific emissions at steady-state dyno engine testing with vehicle emissions on the chassis dynamometer. For each test point the injection strategy was composed by Pilot + Main events.

\section{Results}

\subsection{Description of blending detection procedures}

In order to be widely implemented, the blending detection (BD) strategy needs to be reliable, sufficiently accurate, robust towards biodiesel types and aging, as well as costeffective. Taking in consideration all those key factors, the research activity was focused towards BD strategies that employ sensors already installed on the engine, whose reliability is proven. Therefore, to estimate the blending rate, the strategies combine the information given by sensors with the quantitative information derived from the diesel/biodiesel mixture properties.

In particular, the methodology described by Ciaravino et al. [11], leverages the information carried out by in-cylinder pressure transducers about the actual cycle-averaged IMEP, denoted as IMEP1. This last is obtained by integration of the high-frequency pressure signal, measured by the instrumented glow plugs of each cylinder:

$$
I M E P_{i}=\frac{\oint p_{i} d V}{V}
$$

being $\mathrm{i}$ the $\mathrm{i}^{\text {-th }}$ cylinder and by its following averaging:

$$
I M E P 1=\frac{\sum_{i} I M E P_{i}}{n}
$$

where $\mathrm{n}$ is the number of cylinders.

IMEP1 can be compared, over each engine cycle, with the estimated IMEP produced on the basis of the IMEP mapping performed with pure diesel fuel, as a function of engine speed and accelerator pedal position.

Since the actual IMEP mapped for pure diesel fuel depends, for a certain engine speed and accelerator pedal position, on fuel conversion efficiency (FCE), fuel injected quantity (Qfuel) in terms of mass per cycle, LHV and friction losses (FMEP), the only quantity appreciably impacted by biofuel blending is LHV. In fact, in previous investigations, the authors verified that biodiesel does not significantly affect the engine FCE when the engine runs at the same operating point $[5,8]$, while FMEP, mapped as a function of the operating point and coolant temperature, is characteristic of the whole engine system architecture. Thus, the estimated IMEP from the engine mapping can be defined as IMEP2:

$$
I M E P 2=\frac{F C E \cdot Q f u e l \cdot L H V}{n \cdot V}+F M E P
$$

Hence, two formulations can be leveraged for BD depending on the diesel engine operation mode, with either open-loop or closed-loop IMEP control [11]. In particular, if the engine is in IMEP open-loop control, the Blending Ratio BR is: 


$$
B R=100 \cdot \frac{(I M E P 2 / I M E P 1)-1}{\left(L H V_{\text {diesel }} / L H V_{\text {FAME }}\right)-1}
$$

and the BR is linked to the reduction of IMEP when a biodiesel is burned. Actually, the BR calculation in open loop mode is affected by inaccuracy, due to the drift in engine operating point (i.e. different lambda, heat losses, etc), which impacts the FCE to an extent that does not allow to consider it constant in the working point with IMEP1 (using the diesel/FAME blend) and the estimated working point from engine speed and accelerator pedal position. However, as shown by the authors in two previous papers [5, 8], in open loop control mode, the differences in FCE between diesel and FAME become significant only for the medium load range (e.g. $2500 \mathrm{rpm}$ and 8 bar of BMEP). Therefore, notwithstanding its inaccuracy, this method is suitable for a first rough estimation of the BR of the burned fuel.

The case with the engine closed-loop IMEP control is different; in fact, the BR calculation formula becomes:

$$
B R=100 \cdot \frac{\left(\text { Qfuel }_{\text {FAME } \left./ \text { Qfuel }_{\text {diesel }}\right)-1}\right)-1}{\left(L H V_{\text {diesel }} / L H V_{\text {FAME }}\right)-1}
$$

and it is linked to the increase of fuel consumption, that is to say the Qfuel, when a biodiesel is used.

In closed loop operation mode, the variation of Qfuel is only dependent on the variation of LHV of the used fuel. Since the variation in FCE between diesel and diesel/FAME blend was estimated less than $2 \%$, it is negligible and not affecting the accuracy of the method. For completeness' sake, as reported in other papers [5, 12], the LHV variation from B0 to B100 is about $13 \div 14 \%$, with a small difference among biodiesel feedstock $(\approx 2 \%$ of the B100 value). Another BD methodology, the RAFR (relative air-fuel ratio) method, has been patented [14] and it is based on the comparison between:

- the relative air-fuel ratio RAFR1 estimated from the air and fuel flow rates, and the stoichiometric diesel A/F ratio, assuming the fuel was pure diesel;

- the relative air-fuel ratio RAFR2 directly evaluated through the lambda sensor installed at the engine exhaust, whose composition stems from the engine fuelling with the actual diesel-biodiesel mixture. In particular:

$$
\text { RAFR } 1=\frac{\text { Qair }}{\text { Qfuel }} \cdot \frac{1}{A / F_{\text {st, diesel }}}
$$

being Qair the measured air mass-flow by hot-film sensor and Qfuel the fuel mass-flow interpolated from the injector look-up table (stored in the ECU) as a function of actual injector energizing time and injection pressure, both already used by the ECU. Finally, the A/Fst to be employed in eq. (6) is the one for reference diesel ( 14.6). On the other hand:

$$
\text { RAFR2 }=f\left(V_{-} \text {lambda_sensor }\right)
$$

being the relative air-fuel ratio a monotonic function of the lambda sensor output signal, which shows a weak dependence on the biodiesel type as well as biodiesel-diesel blending ratio. In 
fact, the lambda sensor output signal, for the lean operation which characterizes diesel engines, is a function only of carbon/hydrogen ratio of the fuel, which is almost unchanged from diesel to biodiesel. Hence, the estimated blending ratio BR, can be calculated as:

$$
B R=100 \cdot \frac{(R A F R 2 / R A F R 1)-1}{\left(A / F_{\text {st }, \text { diesel }} / A / F_{\text {st }, \text { FAME }}\right)-1}
$$

In this method the BR evaluation is therefore linked to the variation of RAFR1 between diesel and FAME fuelling due to the Qfuel increase of this latter.

The combination of both the above described methodologies in a real engine can be useful in order to improve the overall accuracy and stability over time by performing cross-checks and confidentiality interval estimation.

\subsection{IMEP BD method results}

As claimed above, also with a reduced accuracy, the BD method is suitable for application when the engine runs in open-loop combustion control, but it is evident that its potential lies on the use of the closed-loop control. So, both to simplify the results analysis and highlight the potentiality of the closed-loop control in $\mathrm{BD}$ method, only the results relative to this last control mode will be shown and discussed in this section.

Before starting the tests campaign, a check of the engine hardware equipments has been done; in particular the ECU injection maps have been checked with a reference fuel flow mass meter (AVL Fuel Balance 731). The check indicated a deviation between ECU fuel flow estimation and fuel balance measurement within the $3 \%$, in line with the normal engine to engine variation from production line.

Figure 2 reports the results of the IMEP method in the nine test points for the detection of $0 \%$ (reference diesel fuel), 20\%, 50\% and 100\% of RME blending level. For mineral diesel, the standard deviation bars have been also reported (in orange), in order to characterize the specific variability of each engine operative point. The blending detection was calculated (in accordance with the above described algorithm), adopting as input variables the fuel consumption calculated by ECU, Qfuel; so these first results represent the current capability of the tested hardware.

The not zero value of BR burning pure diesel fuel derives from the drift between the estimated $Q_{\text {fuelnominal }}$ in the operating point (as mapped in the calibration, function of engine speed and accelerator pedal position and corrected for coolant temperature) and the corrected $\mathrm{Q}_{\text {fuel }}\left(\mathrm{Q}_{\text {fuelactual }}\right.$ ) actuated by ECU by means of measured IMEP value. As it can be seen, the drift is variable point to point and depends on the differences between the laboratory engine configuration in the test cell (as air path layout, auxiliary components, deviation of injector flow characteristics with respect to the nominal values, etc.) and the reference engine configuration as installed on the vehicle.

An overall analysis of the results highlights that the method is able to detect the blending trend, showing an increase of the estimated blends with the blending level. As expected, the method is more and more precise as the fuelling is increased when high speed/load conditions are approached. The highest error was detected at minimum operating point $1000 \mathrm{rpm}$ and zero load, for brevity indicated in the following 1000x0. The reason why the highest BR error occurs at $1000 \times 0$ is the very little injected quantity in this operating condition which, in turn, leads to: 
- $\quad$ an higher injected quantity estimation error because the accuracy and the repeatability of the injection system decreases in the case of small injected quantities;

- an higher IMEP estimation error because of relatively small in-cylinder pressure variations which are more sensitive to sensor noise and accuracy.

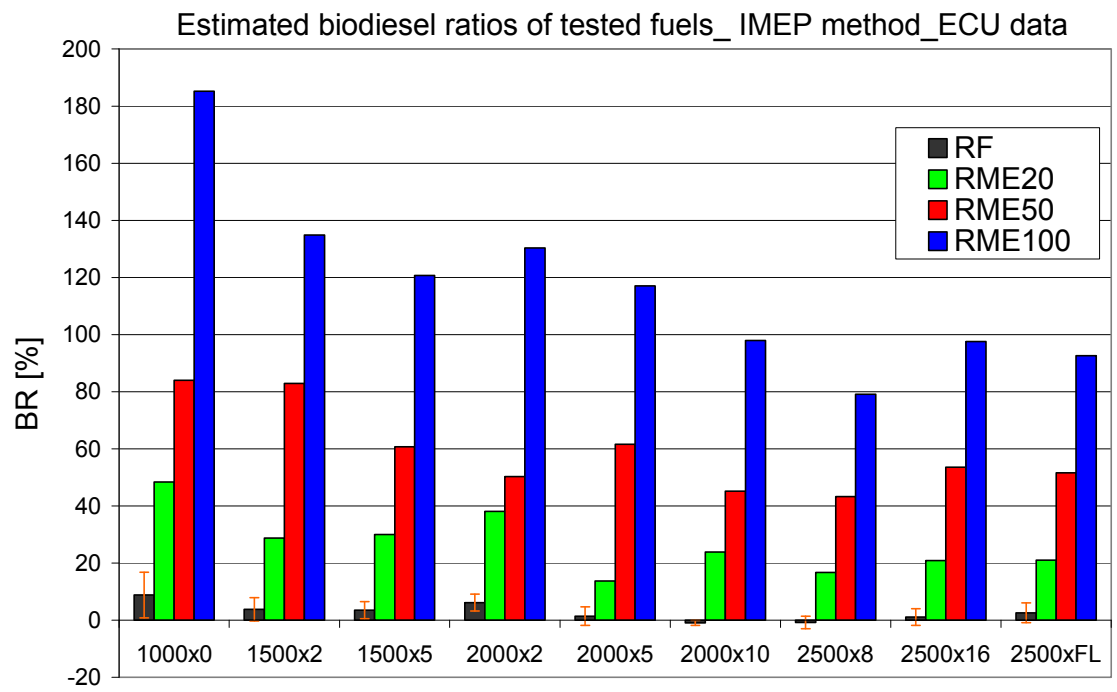

Fig. 2. Blending Ratio by means of IMEP method. ECU input data. Individual test points results.

Furthermore, in this test point, the very low fuelling condition gives very small variation in ET between RF and RME and does not exhibit acceptable results. However, without any correction/refining remedy on the Qfuelnominal with respect to the actual injection quantity, and except the minimum point, the potential of the method is evident also looking at the Blending Ratio values of the first row of Table 3, where the BR average values over the all tested points (except 1000x0) are reported.

\begin{tabular}{|l|l|l|l|l|}
\hline Nominal Blending Ratio & B0 & B20 & B50 & B100 \\
\hline Result mean value w/o injector drift correction [\%] & 2.1 & 24.2 & 56.2 & 108.8 \\
\hline Result mean value with injector drift correction [\%] & 0 & 22.1 & 54.1 & 106.7 \\
\hline Result mean value, fuel mass from the fuel flow meter [\%] & 0 & 17.2 & 49.2 & 102.5 \\
\hline
\end{tabular}

Table 3. BR mean values with IMEP method. ECU input data and fuel flow meter data.

When a learning procedure for $Q_{\text {fuelnominal }}$ correction is implemented in the ECU, the difference between $Q_{\text {fuelactual }}$ and $Q_{\text {fuelnominal }}$ is resettled and the method shows better average results, as reported in the second row of Table 3 . The averaged results show a quite good physical correspondence, so indicating that the method is certainly sensible to the different blending levels.

Looking at the method algorithm (5), taking into account the reset of the drift between nominal and actual value of $Q_{\text {fuel, }}$ the main cause of the inaccuracy of the IMEP method lies 
in the ECU calculation of the fuel consumption, $\mathrm{Q}_{\text {fuelactual. }}$ In fact, the IMEP calculation relies on robust pressure signal integration over cycle, being the measured pressure signal source already accurate (max error of $2 \%$ ) and the sensitivity of IMEP to pressure signal error weak. The accuracy of the ECU for the fuel consumption estimation, in each tested engine point, Qfuelactual, has been evaluated by means of a comparison with the value of consumption measured by the fuel flow meter. This last has been assumed as the "real" value of the fuel consumption, taking into account that the precision of the flow meter instrument has been previously checked.

The results evidenced the presence of a little difference between the Qfuel values derived from the two systems, as detailed in [15]. In general, a random pattern at low and medium engine speeds and loads and an overall ECU overestimation of fuel consumption at high speeds and loads have been observed. However, the average error in all the nine test points (sum of the individual errors) is an overestimation of ECU of $+0.4 \%$.

A further evidence of the sensibility and accuracy of the IMEP method is well illustrated in Figure 3 and in the third row of Table 3, where the results of blending detection for all the individual points and the BR mean values, referred to the IMEP algorithm calculated by using the fuel flow meter measurements are reported, respectively. The orange bars in Figure 3 represent, for each engine operating point, the uncertainty in the blending detection procedure stemming from the statistical error propagation in the calculation chain.

The adoption of the assumed "real" $\mathrm{Q}_{\text {fuel }}$ values leads to an evident improvement of the results; the percentages in the mean BR values of Table 3 clearly show as the BR mean values are very close to the effective level of biodiesel in the tested blends. The maximum drift between real and estimated blend was for B20 and equal to about 3\%, corresponding to a measurement error of $10.5 \%$.

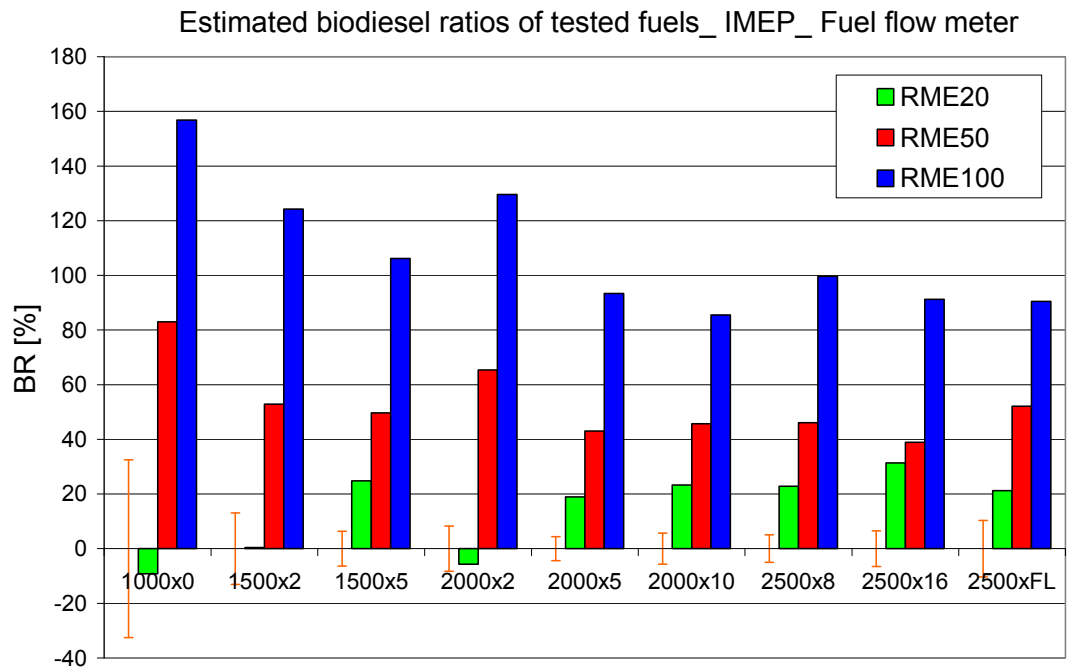

Fig. 3. Blending ratio by means of IMEP method. Fuel flow meter input data. Individual test points results. 
In order to obtain a statistical value of the precision of the fuel consumption provided by ECU, the ECU Qfuel estimation has to be checked in a wide number of engine types. Moreover, to evaluate the global robustness of the IMEP BD method, the accuracy of all components of the measurement chain has to be evaluated in a statistical way. This aspect is out on the aim of the described research activity, which was more addressed to a first screening of the quality of the IMEP BD method, and it will be subject of future work. On the basis of the presented results, the accuracy of the method can be reasonably and preliminarily estimated as $\pm 5 \%$ if a suitable engine operating is chosen to enable the $\mathrm{BD}$ event in the ECU (i.e. high speed, high load area). Such value has to be considered as the minimum diesel/FAME blend detectable by the method. However, BR variation within the accuracy of method gives negligible effects on engine performance and emission, as already proved by past experiences of the authors [5].

\subsection{RAFR BD method results}

As in the case of IMEP BD method, the RAFR BD has been at first applied adopting Qfuel, Qair and $\mathrm{O}_{2}$ estimated by ECU as input variables (see procedures description section), so evaluating the current capability of the hardware.

The results have been summarized in the first row of Table 4, that reports the BR average values over all the test points, with the usual exception of $1000 \times 0$, not considered for the above described reason. The mean values in the first row highlight that the method is sensitive to the different blends, but the results cannot be considered satisfactory, because, due to some inaccuracies in the evaluation of the above-mentioned quantities, the BR values do not have a reasonable physical meaning in all the tested points. However, some considerations can be done to identify the positive and critical aspects and so to unlock the potential of the method.

\begin{tabular}{|l|l|l|l|l|}
\hline Nominal Blending Ratio & B0 & B20 & B50 & B100 \\
\hline Result mean value with ECU data [\%] & 39.9 & 55.6 & 84.3 & 159.8 \\
\hline Result mean value with fuel flow meter data [\%] & 37.3 & 55.4 & 86.1 & 131.4 \\
\hline Result mean value, corrected values [\%] & 0 & 18.1 & 48.7 & 94 \\
\hline
\end{tabular}

Table 4. BR mean values with RAFR method. ECU input data, fuel flow meter data and "corrected" values.

For most of the test conditions the true trend of the tested blends has been grasped. An additional consideration concerns the BR values obtained for B0 (reference fuel). In many kpoints the result of $\mathrm{BR}$ for $\mathrm{B} 0$, in fact, is far from zero and also the average value is not correct (about $40 \%$ instead of the expected $0 \%$ ). Furthermore, the general overestimation of BR results is characterized by an increase of the numerical values increasing the blending level in the fuel, with an inaccuracy approximately proportional to the expected value of blending. It is possible that one or more quantities used in the RAFR procedure are not accurately evaluated by the tested hardware (engine sensor equipment and ECU) and so the method needs an "adjustment" process. The analysis of the inaccuracy of each quantity involved in the algorithm helps in the investigation of the difference between the obtained results and the expected ones. The evaluation of the accuracy of Qfuel estimated by ECU has been already performed. The error of ECU-estimated Qfuel, involved in calculation of both RAFR1 and RAFR2, seems responsible of the observed increase of the numerical values range among the 
tested blends. To confirm this consideration, the results of the method obtained using as Qfuel the values provided by fuel flow meter (instead of the ECU ones) have been reported in the second row of Table 4. An evident improvement is observable. The growing spread of BR values from B0 to B100 disappears and so a more even and physically consistent scaling among the BR values estimated for the four blends is detectable. Hence, the overestimation of the BR results is now only characterized by the offset of the B0 results, that includes the measurement errors of all the other values involved in the algorithm, except the Qfuel ones. Eventually, in order to provide an estimate of the effect of a method recalibration, an "adjustment" process has been done, subtracting the BR value obtained for the B0 from the other blends; the resulted BR values are illustrated in Figure 4 and in the third row of Table 4.

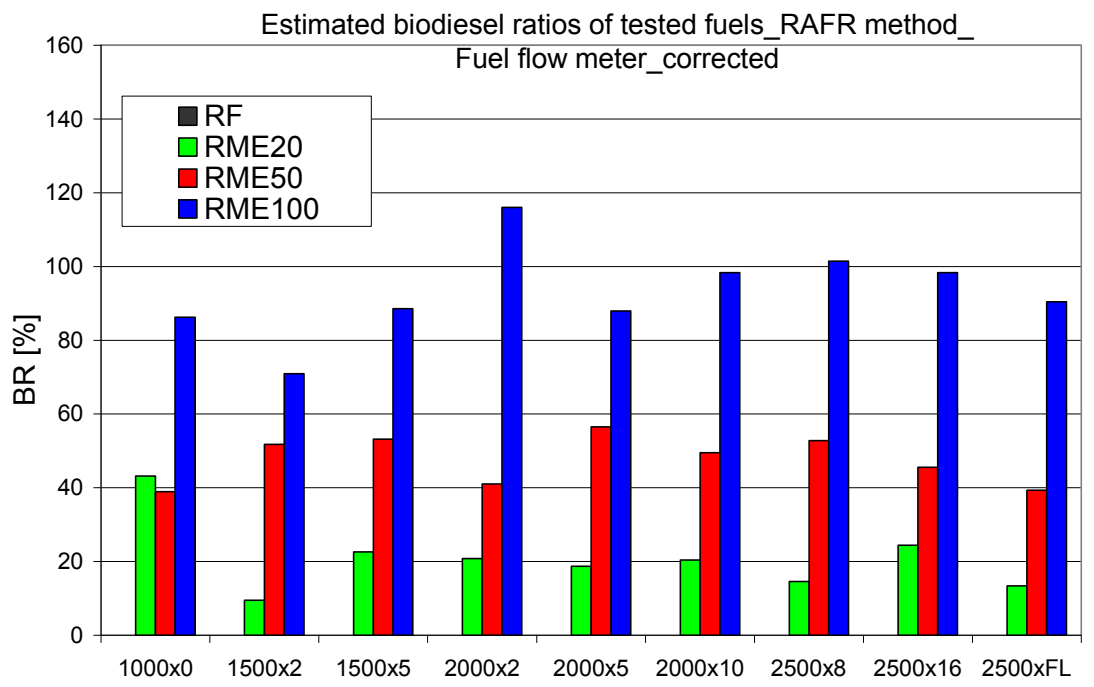

Fig. 4. Blending ratio by means of RAFR method, "corrected" values. Fuel flow meter input data. Individual test points results.

The adjustment allows to a further decisive improvement of the results, as can be observed in Figure 4: only in two test points out of nine $(1000 \times 0$ and $2000 \times 2)$ the results are not yet satisfactory, but the overall blending detection is now good (see third row of Table 4). The "adjusted" values represent the theoretical potential of the RAFR method, following a complete compensation of the uncertainties of the measurements involved (Qair measured by HFM, $\mathrm{O}_{2}$ concentration by LSU, correlation between $\mathrm{O}_{2}$ and RAFR), and could be well approached as engine re-centering strategies are enabled during on-vehicle operation.

The benefits offered by the BD methods are significant. First of all, the achievement of a reliable blending detection is a pre-requisite to exploit the application of the CLCC technology, as described in following sections.

\subsection{Engine emissions improvement by using CLCC system}

The potentiality offered by the CLCC to mitigate the effects of the use of biodiesels has been highlighted in some authors' works $[8,15]$. In particular, it was put in evidence that, thanks to the use of CLCC technology, the drift in engine operating condition, caused by the 
fuelling with a lower LHV fuels, can be avoided. Such drift is the main cause of the correspondent increment of NOx emission, as observable in the next Figure 5.

In the figure, the NEDC engine emission performance estimation without and with the employment of the CLCC technology is reported.

The RME gives slight benefits with respect to diesel fuel in $\mathrm{HC}$ emissions, while the CO emissions are worsened by the high emission at low speed/load conditions. The high CO emissions at low loads are mainly due to the low FCE coming out from the low pilot combustion efficiency and the delayed combustion timing [8]. Looking at the NOx and PM emissions, there are two important factors affecting them. They are the "calibration shift" and the "chemical" factor. The first one controls the NOx emission level in the NEDC test, while the second one is the main driver of the PM exhaust level even if the "calibration shift" factor is not marginal. When CLCC is not applied, both effects can lead to an increase of the level of NOx at the exhaust of about $60 \%$ and to a reduction of PM of about $90 \%$. On the contrary, looking at NOx and PM emission charts on the right side of Figure 5, by means of the implementation of the CLCC without any engine calibration drift, the NOx emissions fall down in the RF STD bar, resetting both the calibration and fuel composition effects. For this last engine control mode, the PM emissions rise with respect to the other control modes but remain very low, about $80 \%$ lower than RF ones.
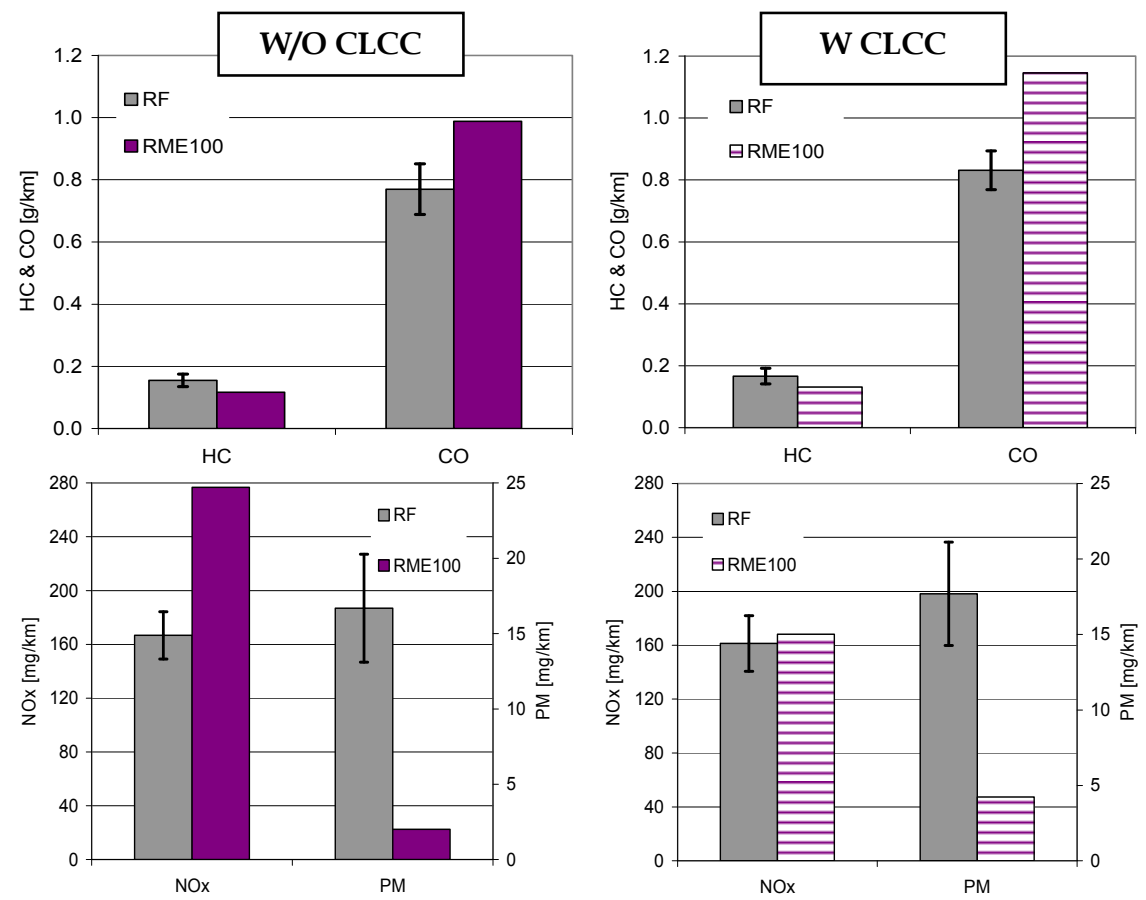

Fig. 5. HC and CO, NOx and PM over NEDC cycle for diesel reference fuel, and RME.

The above described analysis highlights the benefit of the employment of the CLCC technology in modern engines, showing that the use of oxygenated alternative fuels 
characterized by lower A/Fst ratio, like the RME, gives significant PM reduction at nearly constant NOx emission level. Such effect on emission offered by the RME can be seen as a higher EGR tolerability of the fuel. So, it could be exploited by increasing the EGR rate at same exhaust PM loading and further reducing the NOx emissions.

In order to validate this calibration strategy, NOx-PM trade-offs were carried out by varying EGR rate in CLCC mode both for reference diesel fuel and RME. The diagrams in Figures 6, 7 and 8 show the obtained NOx-PM trade-offs in the three engine operating points: $1500 \times 2$, $2000 \times 5$ and $2500 \times 8$.

The PM values were converted from the smoke meter FSN values according to the well consolidated AVL procedure reported in [13]. In the first diagram (1500x2) also the CO trade-off is reported, as at low-speed low-load operating points its emission level becomes critical for the emission targets; in the other two diagrams the BSFC vs NOx trade off is also plotted.

Looking at the Figures 6 and 7, the comparison between the two fuels shows how the EGR recalibration with RME leads to a significant decrease in the exhaust NOx level, permitting to approach the estimated Euro6 NOx emission targets, also reported in the diagrams. The correspondent gap of BSFC between RME and CEC is only dependent on LHV differences between the two fuels and tends to a progressive increase with EGR level, as expected. It is possible to note that also at $2500 \times 8$ burning RME a NOx reduction of about $30 \%$ with respect to the RF at the same PM load on the DPF, was measured, while at 2000x 5 the NOx decrease can reach the value of $68 \%$. Afterwards, the estimation of the biodiesel-diesel blending level by means of the BD method could also permit the automatic recalibration of the EGR map and then a significant improvement in NOx emission without penalties in engine out PM level.

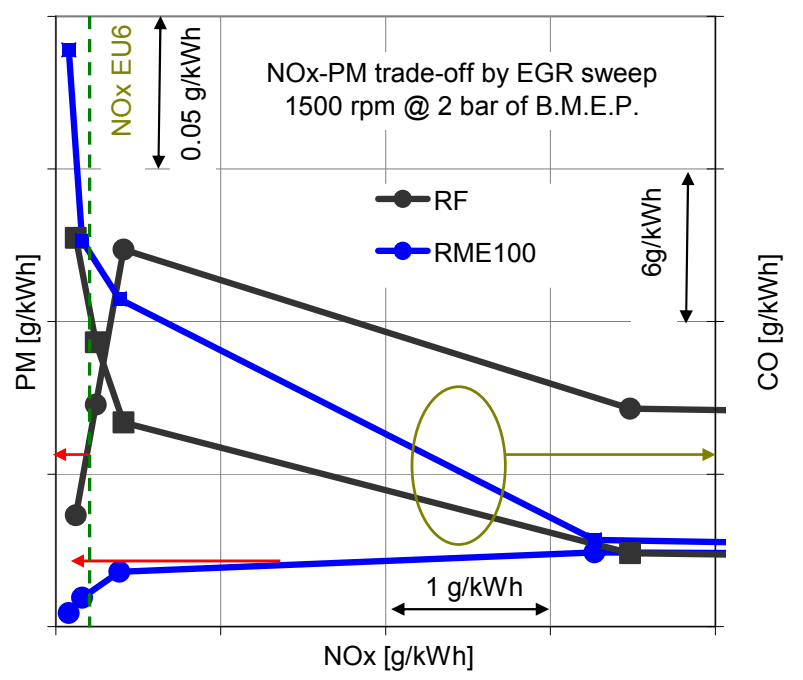

Fig. 6. PM and CO vs NOx trade-off by EGR sweep for RF and RME at 1500x2.

Solid dots markers refer to PM emissions (left axis) while solid squares to CO emissions (right axis). 


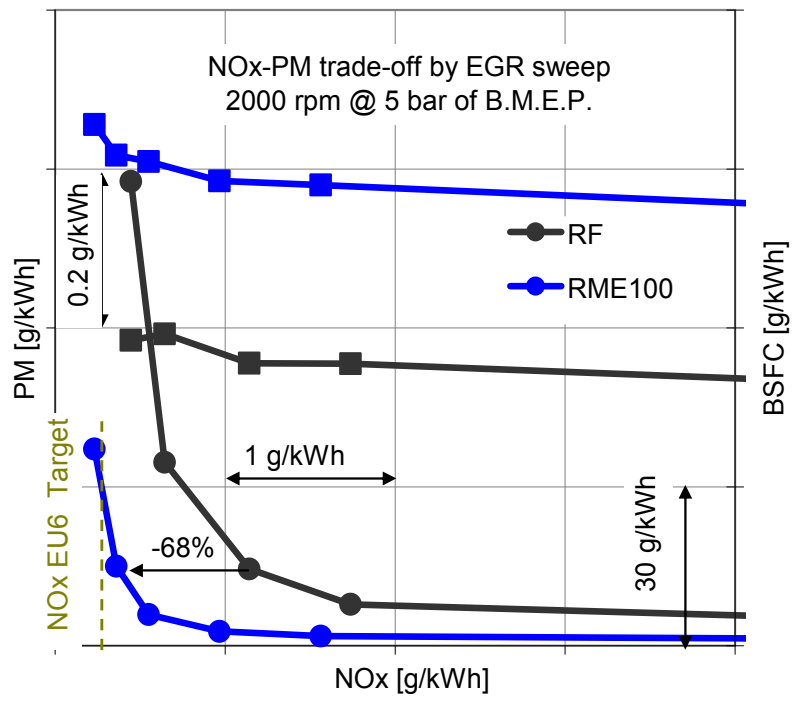

Fig. 7. PM and BSFC vs NOx trade-off by EGR sweep for RF and RME at 2000x5. Solid dots markers refer to PM emission (left axis) while solid squares to BSFC (right axis).

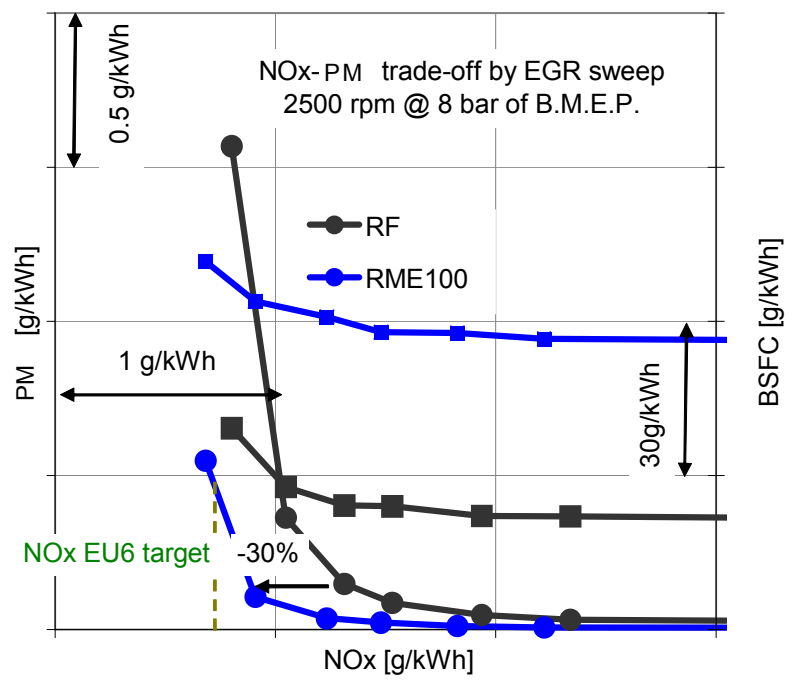

Fig. 8. PM and BSFC vs NOx trade-off by EGR sweep for RF and RME at 2500x8. Solid dots markers refer to PM emissions (left axis) while solid squares to BSFC (right axis). 


\subsection{Engine full load performance improvement with CLCC}

The use of low LHV fuels in diesel engines reduces the full load performance [3, 9]. However, the torque reduction versus speed is dependent not only from the LHV reduction of the FAME, but also on the engine technology and the engine operating characteristics at full load. As an example, like it has been described by Millo et al. [9] about the effects of the biodiesel usage in small displacement diesel engines, the particular operating characteristics of the turbocharger in the low speed range (featuring turbo rack always totally closed and no boost margin) cause a reduction of the maximum boost pressure with a consequent full torque decrement up to $30 \%$ when pure FAME is employed, due to the turbine inlet enthalpy decrease.

The interaction between FAME characteristics and full load engine performances has been evaluated also for the engine used in the present work. The diagram in Figure 9 reports the torque values for reference fuel and RME both in OLCC and in CLCC modes. As expected, when CLCC is disabled, and so the injected fuel quantity at full load is volume limited, a torque reduction burning FAME is present in the whole engine speed range and it is higher at the highest engine speed conditions. The torque reduction is about $3-4 \%$ between 1250 $1750 \mathrm{rpm}$, while at medium engine speed is progressively increased, reaching $7-8 \%$ above 3000rpm. In CLCC mode such differences are completely absorbed, confirming the capability of IMEP closed-loop control to compensate any influence of the fuel properties on the engine maximum torque curve. As a matter of fact, at every engine speed, the deviations between diesel and biodiesel in CLCC mode are less than one percent, so they can be easily considered inside the test to test repeatability.

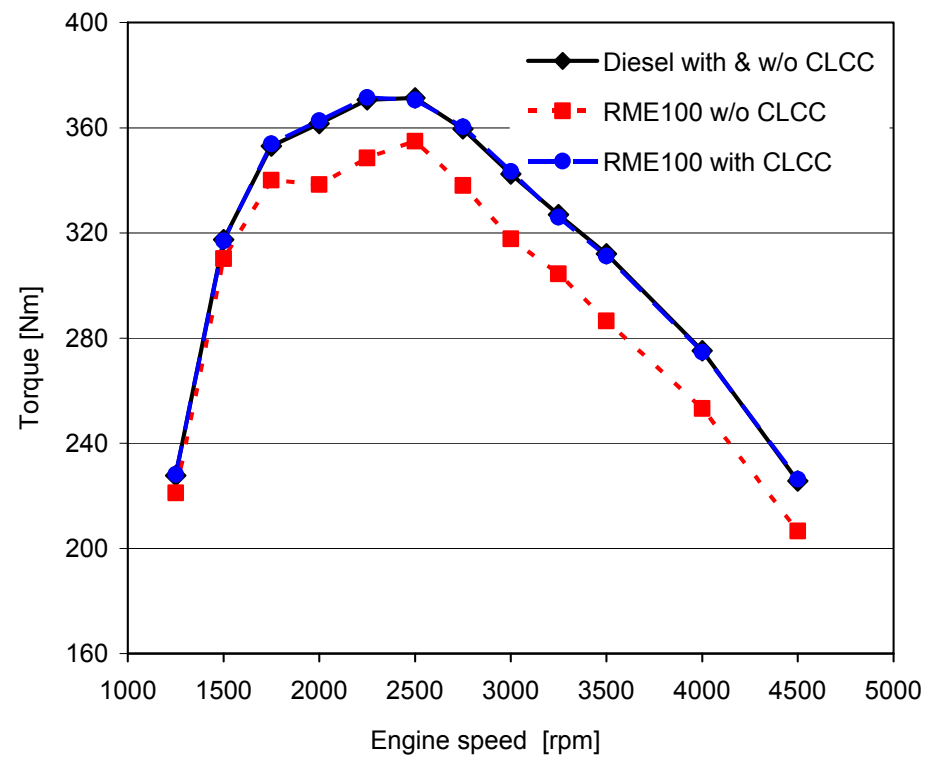

Fig. 9. Engine maximum torque curve comparison versus engine speed. 

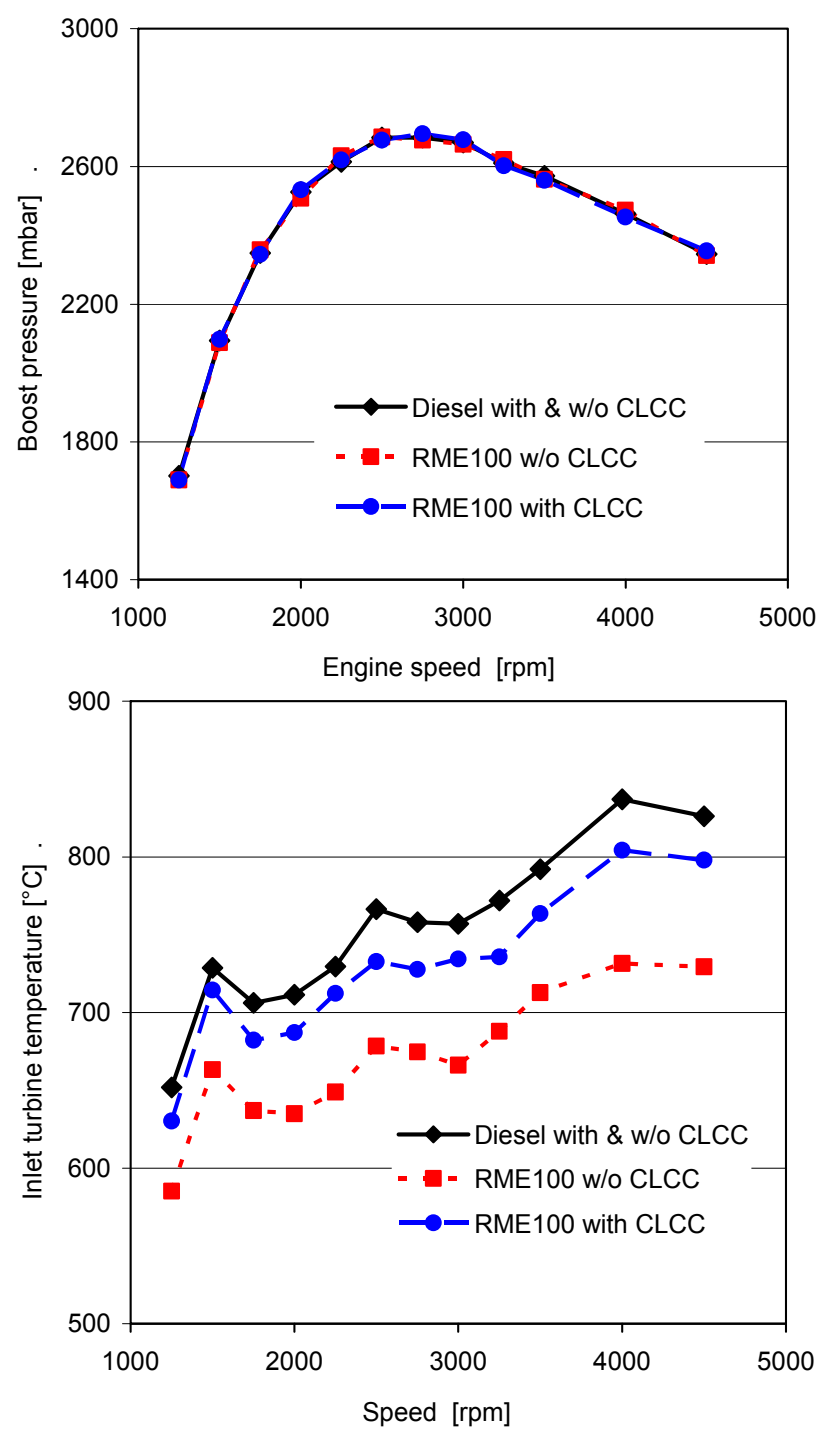

Fig. 10. Boost pressure (upper) and exhaust gas temperature (bottom) comparison versus engine speed.

Even considering the intake and exhaust manifold conditions, as represented in Figure 10 by boost pressure and exhaust temperature, very similar engine operating conditions between petrol diesel and RME are reached when CLCC technology is enabled.

There are no apparent boost pressure differences between RF and RME results in both the combustion control modes. This suggests that turbocharger is able to provide the same boosting level even employing FAME. The reduction of exhaust gas temperature when CLCC is disabled is directly linked to the reduction of chemical energy introduced with fuel 
(lower LHV). However, even when CLCC is enabled, a slight reduction in engine-out gas flow temperature was measured. This phenomenon is linked both to the advanced main injection timing to be used for biodiesel in order to keep constant the combustion phasing (MBF50\% value), due to its extended injection duration (lower LHV) as well as to its higher thermal capacity which reduces charge temperature during fuel evaporation.

Generally, the three main limitations on the maximum attainable torque versus engine speed are the maximum cylinder peak pressure, maximum exhaust gas temperature upstream the turbine and maximum engine out smoke level. In particular, in the low engine speed range, and especially for the maximum attainable low-end torque, the smoke emission is the limiting parameter. Nevertheless, for FAME fuelling, the engine works at same maximum torque in the low speed range with significant lower smoke emission with respect to the diesel fuel because of its oxygen content and lower A/F stoichiometric ratio. Such result is clearly observable in the diagrams of Figure 11, that reports smoke emissions for both fuels and combustion control modes.

In Figure 11 it is notable that also in CLCC mode the smoke emissions of RME are always lower than diesel fuel ones although, due to the increase in power delivered, the increment is bigger than in NEDC cycle based comparison (Fig. 5). Such result suggests the possibility to increase the maximum attainable full torque where the exhaust smoke emission is the limiting parameter. Specific tests were performed with this objective, the re-calibration of the engine in order to increase the full torque until the same smoke emission level of the diesel fuel was reached. Figure 12 shows the result in the engine speed range 1250-2250 rpm. A torque increment of about $4 \%$ was attained at low engine speed (see left diagram of Figure 12) and at same engine out smoke emissions (see right diagram of Figure 12). Such result represents a good improvement in engine performance. As mentioned, this increment is obtained by calibration adaptation to a known biodiesel blending ratio in the fuel and, therefore, highlights the importance of the BD strategies.

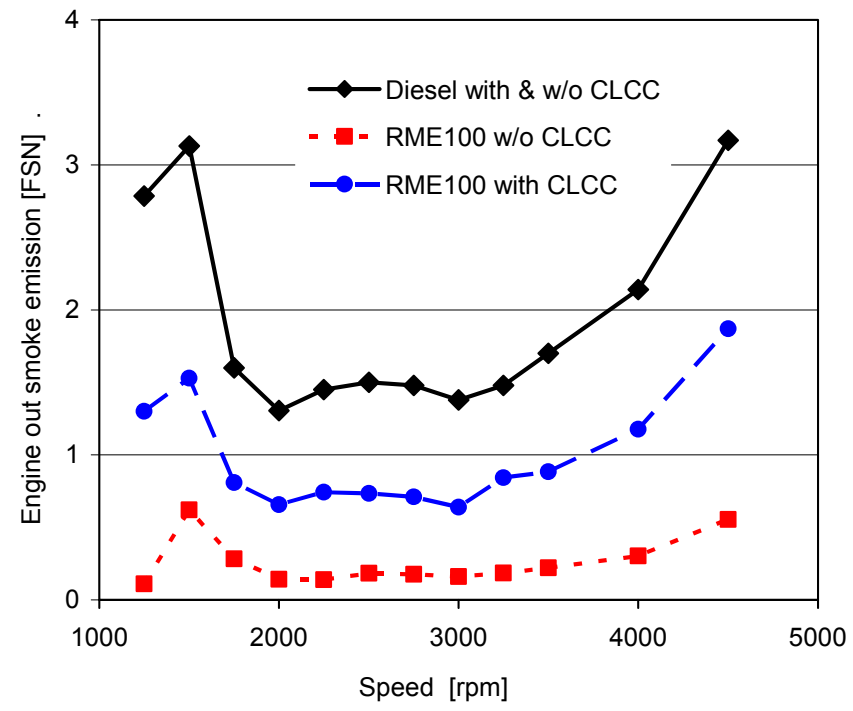

Fig. 11. Smoke emissions versus engine speed for both fuels and both combustion control modes. 

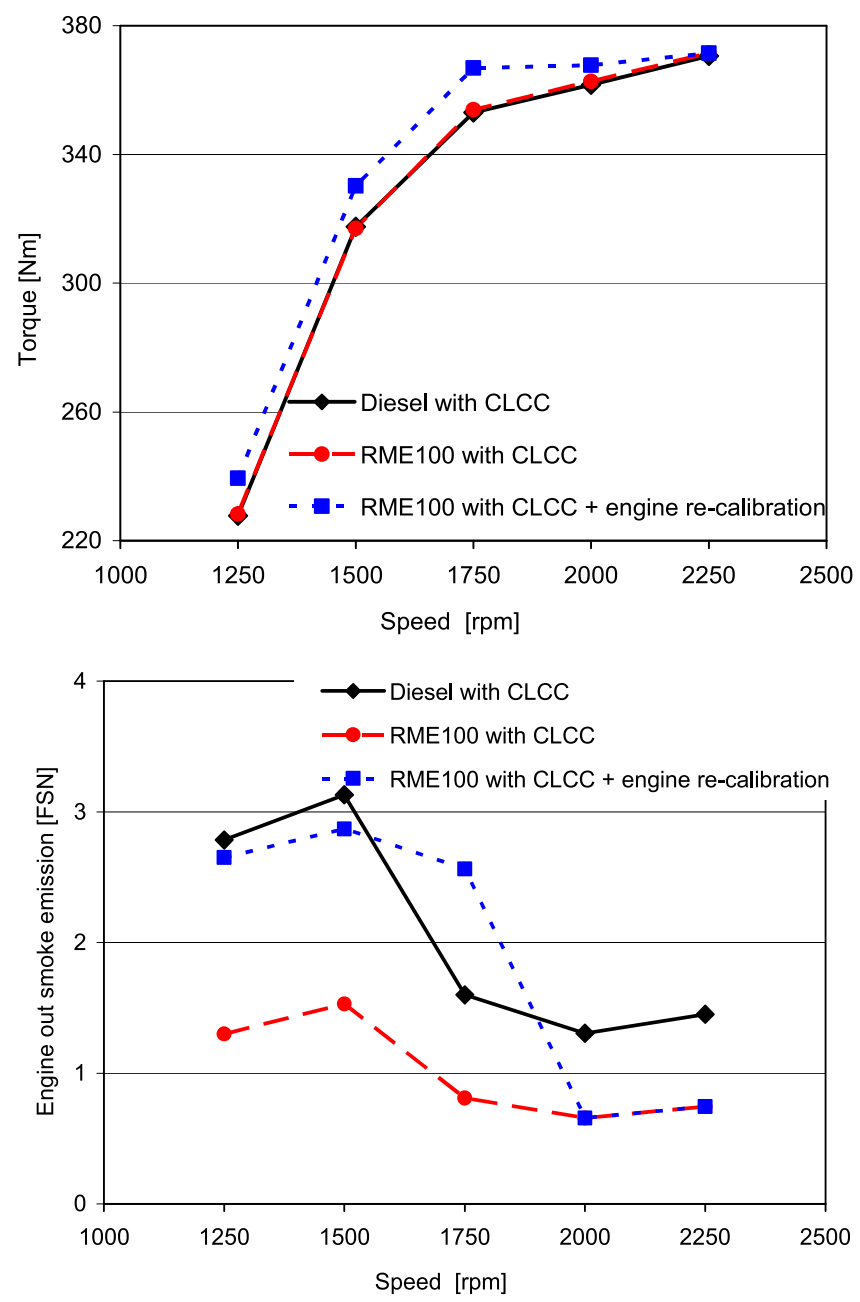

Fig. 12. Low-end torque curve (upper) and engine out smoke emissions (bottom) for reference diesel fuel, RME in CLCC mode, RME in CLCC mode and engine re-calibration.

\section{Conclusions}

The present chapter has been dedicated to illustrate the potentiality offered by the electronic control technology to fully exploit the biodiesel use in automotive diesel engine.

In particular, based on the employment of innovative biodiesel blending detection methodologies, the capability of closed loop combustion control to improve both pollutant emissions and full load engine performance has been investigated.

Two blending detection methods have been described and tested, assessing the potential offered by the production sensor system to detect the blending level of biodiesels. The IMEP method is certainly sensitive to the different blending levels, showing a good physical 
correspondence with the effective level of biodiesel in the tested blends. By employing corrective remedy or learning procedures for fuel flow estimation, the accuracy of the method could be further improved.

The method based on lambda and air mass flow sensors (RAFR), although well reflects the actual trends, shows a more imprecise results, and needs "corrections" of some parameters involved in the algorithm and a deep investigation of the accuracy of different parts of the experimental system.

The use of a blending detection method opens new possibilities on the automatic adaptation of the engine calibration to the fuel blend characteristics. In particular, it has been showed that, thanks to the closed loop combustion control, just with a simple optimization of the EGR calibration map for low "sooting" fuels, significant improvements are possible on NOx emissions at same engine out concentration of particulate matter.

The potentiality offered by the CLCC technology to reset the torque loss burning biodiesel has been illustrated. It was also put in evidence the possibility to exploit the very low smoke emissions burning FAME fuels, increasing the low-end max torque curve with respect to a conventional diesel fuel; also in this sense the quantitative information of the BR is important.

Based on the discussed results, the authors believe that the benefits offered by the BD methods are significant. All this represents a fundamental step towards the development of flex-fuel engines that, by means of the adaptation of calibration parameters to the optimal set for the actual burned fuel, can minimize their environmental impact.

Finally, it is important to clarify that this chapter has presented only the functional assessment of blending detection methodology and adaptation strategy: this represents the first step of a new technology development. While their potential has been verified, in the next future additional work has to be performed to define how to realize robust blending detection and the related engine drift in the real driving conditions over a significant vehicle mileage and also to assess the robustness of the system when exposed to high rate of biodiesel fuelling for a long time.

\section{Acknowledgment}

A special thank goes to Mr. Giovanni Alovisi, Mr. Giuseppe Corcione, Mr. Augusto Piccolo and Mr. Roberto Maniscalco for their technical assistance in the engine testing.

\section{References}

[1] Sheehan, J.; Camobreco, V.; Duffield, J.; Graboski, M. \& Shapouri, H. (1998). An Overview of Biodiesel and Petroleum Diesel Life Cycles, National Renewable Energy Lab, May. Available from http:// devafdc.nrel.gov/pdfs/3812.pdf

[2] Report of the Commission of the European Communities, Biofuels Progress Report, Bruxelles, 2007. Available from: http://www2.epia.org/documents/NL_0711_037.pdf

[3] Lapuerta, M.; Armas, O. \& Rodríguez-Fernández, J. (2008). Effect of biodiesel fuels on diesel engine emissions, Progress in Energy Combustion Science, Vol. 34:198-223

[4] Kawano, D.; Hajime, I.; Yuichi, G.; Akira, N. \& Yuzo, A. (2006). Application of Biodiesel Fuel to Modern Diesel Engine, SAE Tech. paper 2006-01-0233 
[5] Beatrice, C.; Di Iorio, S.; Guido, C.; Mancaruso, E.; Vaglieco, B.M. \& Vassallo, A. (2009). Alternative Diesel Fuels Effects on Combustion and Emissions of an Euro4 Automotive Diesel Engine, SAE Tech. paper 2009-24-0088

[6] DIRECTIVE 2009/28/EC OF THE EUROPEAN PARLIAMENT AND OF THE COUNCIL, Bruxelles, 2009. Available from: www.energy.eu/directives/pro-re.pdf

[7] Soltic, P.; Edenhauser, D.; Thurnheer, T.; Schreiber, D. \& Sankowski, A. (2009). Experimental investigation of mineral diesel fuel, GTL fuel, RME and neat soybean and rapeseed oil combustion in a heavy duty on-road engine with exhaust gas aftertreatment, Fuel, Vol. 88: 1-8

[8] Beatrice, C.; Guido, C. \& Di Iorio, S. (2010). Experimental analysis of alternative fuel impact on a new 'torque-controlled' light-duty diesel engine for passenger cars, Fuel, Vol. 89: 3278-3286

[9] Millo, F.; Bianco, A.; Vezza D.; Vlachos, T.; Ciaravino, C.\& Vassallo, A. (2010) Biodiesel fuelling impact on performance and dilution of Euro5 small displacement passenger car diesel engine, conference proceedings of SEET 2010, Jun 29th-Jul 2th, Bari, Italy,

[10] Mueller, C.; Ras Robotti, B.; Wesslau, M.; Drangel, H., Agricola, U.; Catanese, A. \& Manta, E. (2009). Opel's new 2.0L BiTurbo Diesel engine with highly innovative CleanTech combustion concept, MTZ Worldwide, Vol. 12

[11] British Patent Application GB 0918272.6, 2009, Inventors: Ciaravino, C., Guglielmone, F., and Vassallo, A.

[12] Rakopoulos, C. D.; Antonopoulos, K.A.; Rakopoulos, D.C.; Hountalas, D.T. \& Giakoumis, E.G. (2006). Comparative performance and emissions study of a direct injection Diesel engine using blends of Diesel fuel with vegetable oils or bio-diesels of various origins, Energy Conversion and Management, Vol. 47: 3272-3287

[13] AVL documents, Smoke value measurement with filter paper method, available from: https:/ / www.avl.com/c/document_library/get_file?uuid=2b39210c-6937-43e4b223-b5c2c11f91ac\&groupId=10138.

[14] Serra, G., and De Serra, M., "Method for Recognizing the Fuel Type in a Diesel Engine", European Patent EP 1854982.A1, 2007.

[15] Guido C., Beatrice C., Di Iorio S., Napolitano P., Di Blasio G., Vassallo A., Ciaravino C. "Assessment of Closed-Loop Combustion Control Capability for Biodiesel Blending Detection and Combustion Impact Mitigation for an Euro5 Automotive Diesel Engine" SAE Tech. paper 2011-01-1193. 


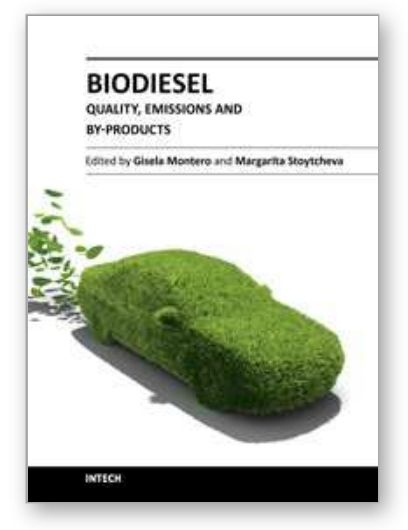

\author{
Biodiesel- Quality, Emissions and By-Products \\ Edited by Dr. Gisela Montero
}

ISBN 978-953-307-784-0

Hard cover, 380 pages

Publisher InTech

Published online 16, November, 2011

Published in print edition November, 2011

This book entitled "Biodiesel: Quality, Emissions and By-products" covers topics related to biodiesel quality, performance of combustion engines that use biodiesel and the emissions they generate. New routes to determinate biodiesel properties are proposed and the process how the raw material source, impurities and production practices can affect the quality of the biodiesel is analyzed. In relation to the utilization of biofuel, the performance of combustion engines fuelled by biodiesel and biodiesels blends are evaluated. The applications of glycerol, a byproduct of the biodiesel production process as a feedstock for biotechnological processes, and a key compound of the biorefinery of the future is also emphasized.

\title{
How to reference
}

In order to correctly reference this scholarly work, feel free to copy and paste the following:

Carlo Beatrice, Silvana Di Iorio, Chiara Guido and Pierpaolo Napolitano (2011). The Key Role of the Electronic Control Technology in the Exploitation of the Alternative Renewable Fuels for Future Green, Efficient and Clean Diesel Engines, Biodiesel- Quality, Emissions and By-Products, Dr. Gisela Montero (Ed.), ISBN: 978953-307-784-0, InTech, Available from: http://www.intechopen.com/books/biodiesel-quality-emissions-and-byproducts/the-key-role-of-the-electronic-control-technology-in-the-exploitation-of-the-alternative-renewable-f

\section{INTECH}

open science | open minds

\section{InTech Europe}

University Campus STeP Ri

Slavka Krautzeka 83/A

51000 Rijeka, Croatia

Phone: +385 (51) 770447

Fax: +385 (51) 686166

www.intechopen.com

\section{InTech China}

Unit 405, Office Block, Hotel Equatorial Shanghai

No.65, Yan An Road (West), Shanghai, 200040, China

中国上海市延安西路65号上海国际贵都大饭店办公楼405单元

Phone: +86-21-62489820

Fax: +86-21-62489821 
(C) 2011 The Author(s). Licensee IntechOpen. This is an open access article distributed under the terms of the Creative Commons Attribution 3.0 License, which permits unrestricted use, distribution, and reproduction in any medium, provided the original work is properly cited. 